\title{
Design and Analysis on a Pressure Control Device to Setting Load for Hydraulic Support in Coal Face
}

\author{
Cao Lianmin ${ }^{*}, 1,2$, Zhang Fan ${ }^{1}$, Chen Weiyang ${ }^{1}$ and Chen Lianjun ${ }^{2}$ \\ ${ }^{I}$ College of Mechanical and Electronic Engineering, Shandong University of Science and Technology, Qing Dao, \\ 266590, China \\ ${ }^{2}$ State Key Laboratory of Mining Disaster Prevention and Control Co-Founded by Shandong Province and the Ministry \\ of Science and Technology, Shandong University of Science and Technology, Qing Dao, 266590, China
}

\begin{abstract}
This paper mainly designs a device for improving setting load of hydraulic support. The device could enhance the pressure of bottom cavity of the stand column in hydraulic support, decrease the late bearing time of stand column of hydraulic support, shore the roof of coal face effectively, prevent the roof fall caused by separating the roof of wall rock untimely from the layer, and ensure the safety production in the coal facing, with the circumstance that the structure of liquid valve bank of hydraulic support isn't changed and that it has no influence on the normal working of liquid-inlet and rising support. The device using the techniques of hydraumatic and machinery, of which the structure is simple, safe and reliable, is convenient for the work at the underground coal mine. Through the simulated analysis for hydraulic circuit of hydraulic support and the field test, the hydraulic system of hydraulic support is stability with no larger vibration and has a better effect on pressurizing, after using the device. So, the automatic pressure control device to setting load has good popularization and application value.
\end{abstract}

Keywords: Coal face, Hydraulic support, Setting load, Pressure control device, Coal mine, Safety production.

\section{INTRODUCTION}

Hydraulic support plays a vital role on the safety production for coal mine, and is the key equipment for realizing high yield and high efficiency in the coal face. The function of hydraulic support in the coal face is that to support and control the roof of coal mine effectively and to ensure safety work space for worker operation and machine running. But, in the practical work of coal cutting, on account of such reasons as the pipeline of feed liquid from emulsion pump station to coal face lengthened by linear expansion of the length of coal face, the on-way resistance loss of pipeline increased, pipeline weeping and short clamping time for using manual operation, the setting load can't reach the designed value, and the drag time of stand column is lengthened. So, hydraulic support couldn't shore the roof effectively, and the potential safety hazard is brought in the coal face. Therefore, to decrease the roof fall accident caused by that the roof of coal face is separated from layer untimely to break the integrality, and to ensure the safety of coalmine production, it's very significant to design the pressure control system for increasing setting load [1].

\section{MATERIALS AND METHODOLOGY}

\subsection{Design Thought}

The project thought is to design a device that can improve the setting load of hydraulic support automatically.

\footnotetext{
*Address correspondence to this author at the College of Mechanical and Electronic Engineering, Shandong University of Science and Technology, Qian Wangang Road No. 579, Qing Dao, Postcard: 266590, China; Tel: 13793293776; E-mail: skdclm@163.com
}

This device is placed between commutation control valve and stand column of hydraulic support, and is able to ensure the setting load of hydraulic support to achieve the setting value required in the case that the structure of reversing valve isn't changed and the normal work for raising hydraulic support isn't influenced. The automatic pressure control device to setting load adopts the techniques of hydraumatic and machinery. The structure is simple, safe and reliable. And it is convenient for the work of fully mechanized coal mining face. When the setting load can't satisfy the design requirement for the process of raising hydraulic support, the device is capable to do the self-motion fluid infusion and pressure boost, improves the setting load of hydraulic support, and decreases the drag time of stand column. Thereby, it's effective that the device prevents that the roof of coal face is separated from layer untimely, and improves the shoring performance of hydraulic support, and ensures the safety production of coal face [2].

Characteristics of the automatic pressure control device to setting load is that a automatic pressure increasing valve is connected in parallel with control loop of inferior liquid inlet for each stand column. To manipulate the reversing valve when requiring setting prop, high pressure emulsion from liquid inlet pipeline should pass the pilot valve, and the pilot operated check valve provides the liquid directly for inferior cavity of stand column. Because of the stand column that is being in the condition of setting prop, the pressure of feed inlet is relatively low, and the pressure cylinder doesn't move. The stand column is in the condition of quick setting prop; when the top beam of hydraulic support touches with the roof, the pressure of inferior cavity of stand column begins to be elevated. When the pressure of inferior stand 
column reaches the pressure of feed inlet, the pressure cylinder begins to move, and can reach the setting value within ultra-short time.

\subsection{Structural Design}

The structure of the automatic pressure control device to setting load for hydraulic support consists of pressure cylinder, pressurizing control valve, safety valve, valve body, check valve and elbow. When to be assembled, pressurizing control valve, safety valve and safety valve will integrate in the valve body, and elbow is welded with the cylinder block and valve body, and pressure cylinder is welded with valve body [3, 4].

The structure of the automatic pressure control device to setting load for hydraulic support is shown in Fig. (1).

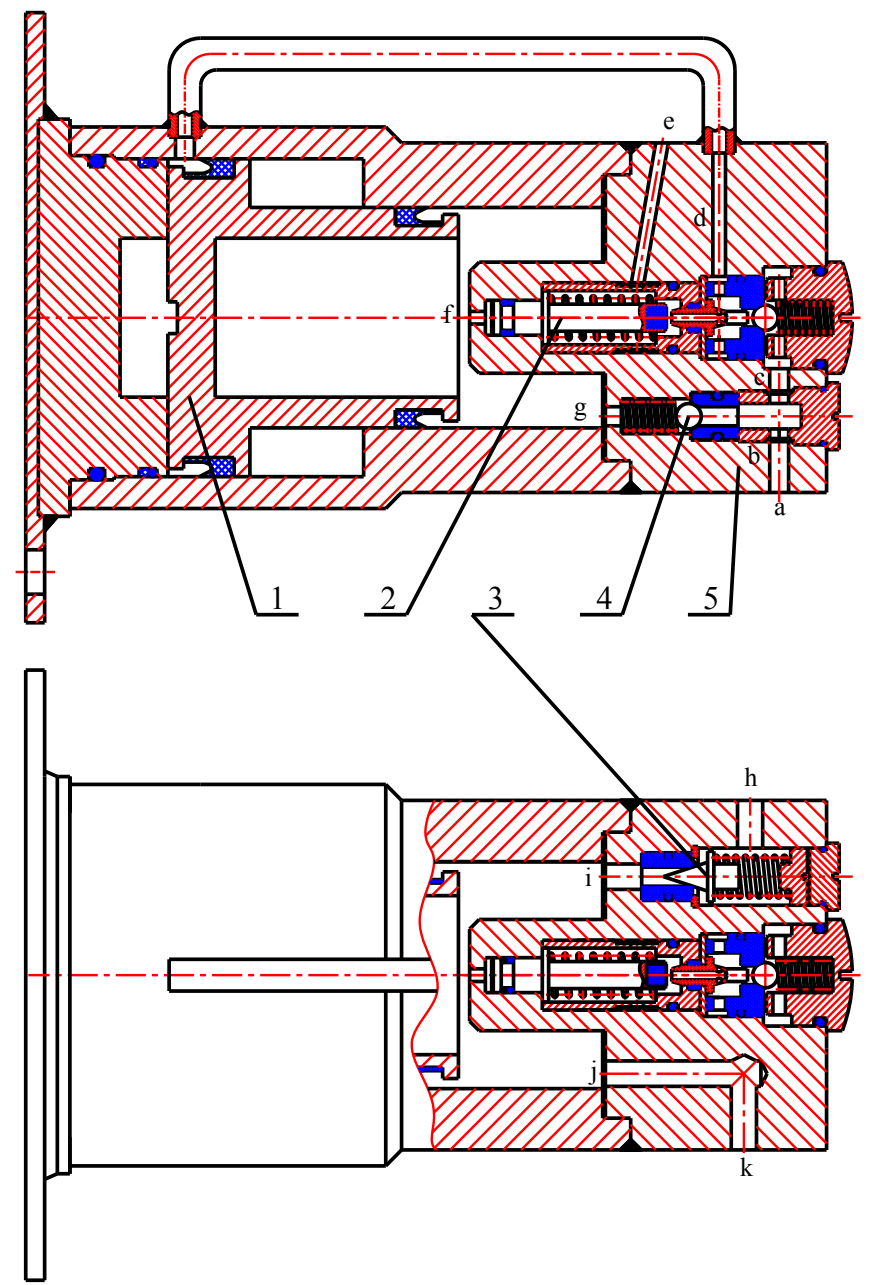

Fig. (1). Discrete modeling of crack propagation. 1-pressure cylinder, 2-pressurize control valve, 3-safety valve, 4-check valve, 5-valve body.

The pressure cylinder includes pedestal, connection steel wire, pedestal anti-extrusion ring, $\mathrm{O}$ ring, $\mathrm{Y}$ ring, cylinder block, piston, $\mathrm{Y}$ ring, and elbow. The pressurized control valve consists of $\mathrm{O}$ ring, anti-extrusion of big ejector rob, big ejector rob, spring, spring pocket, $\mathrm{O}$ ring, sealing gasket, junk ring, little ejector rob, O ring, steel ball, spring, spring plate, valve seat, $\mathrm{O}$ ring, anti-extrusion ring of spring plate and $\mathrm{O}$ ring. The check valve is composed of drain cap, $\mathrm{O}$ ring, valve seat, $\mathrm{O}$ ring, steel ball and spring. The safety valve contains $\mathrm{O}$ ring, plug, pressure regulating screw, spring, cone valve, check ring, valve seat and $\mathrm{O}$ ring.

\subsection{Working Principle}

Emulsion, from emulsion pump station, flows into pipe $b$ and $\mathrm{c}$ via pipe a. Emulsion in pipe $\mathrm{c}$ compresses the steel ball of pressurized control valve on the valve seat, and emulsion is enveloped in pipe c. Still, emulsion flowing into pipe b opens steel ball of check valve, and flow into the right cavity of pressure cylinder. Then, emulsion going through the right cavity of pressure cylinder will be separated into three parts: a part of emulsion contacts with hydraulic support through pipes $\mathrm{j}$ and $\mathrm{k}$; other part impacts directly on big ejector pin through pipe $\mathrm{f}$; the third part affects the piston of pressure cylinder. The working process of total auto-pressurized equipment can be divided into setting prop and pressurizing $[5,6]$.

\subsubsection{Setting Prop}

Emulsion flowing into the right cavity of pressure cylinder from emulsion pump station communicates with the inferior cavity of hydraulic support through pipes $\mathrm{j}, \mathrm{k}$ and the reversing valve of hydraulic support. The system supplies liquid for hydraulic support, and the top beam of hydraulic support will contact with roof after hydraulic support is raised by liquid supplied. In the meantime, emulsion flowing into the right cavity of pressure cylinder from emulsion pump station drives the piston of pressure cylinder to left position. Emulsion in the left cavity of pressure cylinder, which flows to the external of device through elbow, pipe d, the mesopore of little ejector rob, spring pocket and pipe e, drives the piston of auto-pressurized initial force guarantee equipment to the leftmost end place.

\subsubsection{Pressure Boost}

As the top beam of hydraulic support contacting with roof, the emulsion pressure in the right cavity of pressure cylinder will increase [7]. The big ejector rob of pressurized control valve will be moved to the right by emulsion in the pipe $\mathrm{f}$, and promote the little ejector rob to turn on the steel ball. At this point, emulsion can't flow to the external of device because of that the sealing gasket on the pressurized control valve seals the mesopore of the little ejector rob. In this way, emulsion, from emulsion pump station, and pipes a, and c, will flow into the left cavity of pressure cylinder through valve seat, pipe $\mathrm{d}$ and elbow to shift the piston to right. Now, the emulsion pressure of right cavity of pressure cylinder is improving and reaching rapidly the value required by initial support for stand column of hydraulic support. The total process of setting prop will be finished. If pressure is larger than initial force for support, emulsion in the right cavity of pressure cylinder makes the cone valve to open through pipe $i$, and flow out through pipe $h$, and safety valve begins to overflow, so that the device supplies the max emulsion pressure value for stand column and the normal work of hydraulic support is guaranteed. If the emulsion pressure from emulsion pump station is satisfied with the working requirement for hydraulic support, the autopressurized initial force guarantee equipment won't work for pressure boost, and emulsion flows into the stand column 
through reversing valve and the device. The normal work of hydraulic support is also guaranteed.

\subsection{The Model of Hydraulic Control Circuit}

The hydraulic control circuit of prop is shown as Fig. (2). High pressure liquid from emulsion pump station flows into the inferior cavity of stand column of hydraulic support through reversing valve and check valve, and stand column rises up quickly. At this moment, the pressure of inferior cavity of stand column is lesser. After that top beam of hydraulic support touches with the roof, so that stand column is no longer elevated. Liquid volume in the inferior cavity of stand column decreases sharply, and pressure of the inferior cavity is improved. And, on account of compression ratio of emulsion in the inferior cavity of stand column, some liquid is required to supply in order to satisfy the setting load for hydraulic support $[8,9]$.

The hydraulic control circuit of auto-pressurized initial force guarantee equipment is shown in Fig. (3).

The characteristic of the hydraulic control circuit is that the automatic pressure increasing valve is connected in parallel to the control loop of inferior liquid inlet of every stand column [10]. The model of the hydraulic control circuit of auto-pressurized initial force guarantee equipment consists mainly of two check valves, a pressure cylinder and a two-position three way pilot operated directional control valve. When the inlet pressure of auto-pressurized initial force guarantee equipment is lower than the set pressure of two-position three way pilot operated directional control valve, liquid from inlet pipeline will discharge directly from pressure increasing valve entrance, check valve and pressure increasing valve exit, and pressure cylinder will have no function. When inlet pressure of auto-pressurized initial force guarantee equipment is larger than set pressure, twoposition three way valve in the right position will work. And pressure cylinder also begins to move so as to improve the pressure [11].

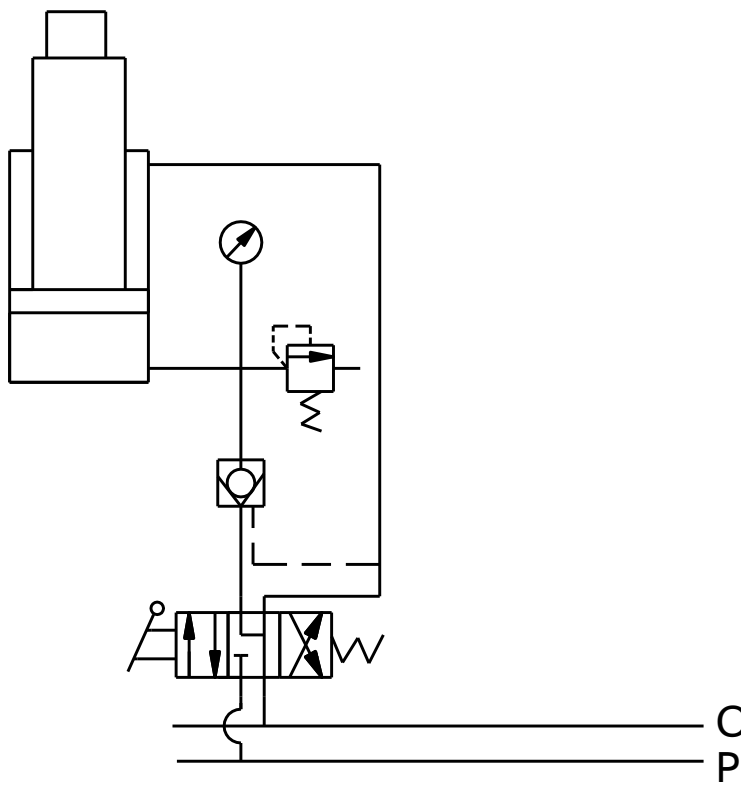

Fig. (2). The hydraulic control circuit of prop.

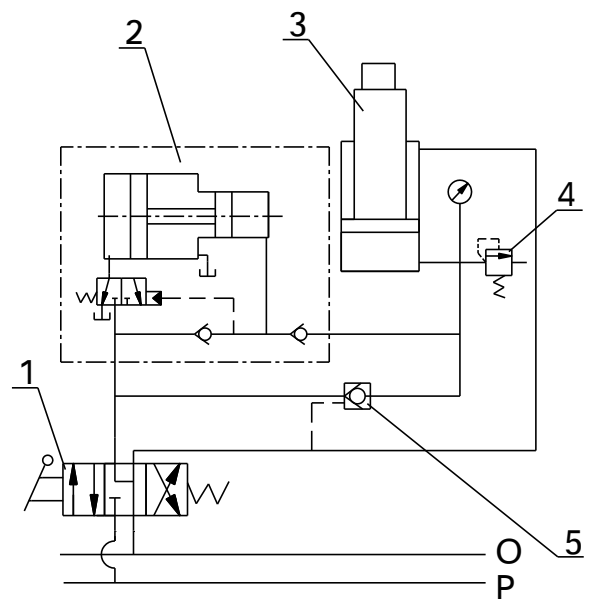

Fig. (3). The hydraulic control circuit of auto-pressurized initial force guarantee equipment. 1-Control valve, 2-Auto-pressurized valve, 3-Prop, 4-Safety valve, 5-Pilot controlled one-way valve

The schematic diagram of auto-pressurized initial force guarantee equipment is shown as Fig. (4).

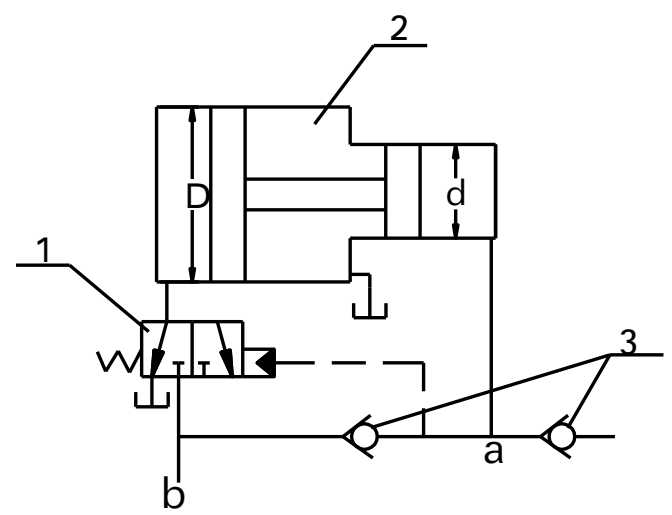

Fig. (4). The principle of auto-pressurized valve. 1-Hydraulic control two three-way valve 2-Pressurized cylinder 3-One-way valve a-Fluid inlet port b-Fluid outlet port.

\subsection{Simulated Analysis of Auto-Pressurized Initial Force Guarantee Equipment}

The simulation model of auto-pressurized initial force guarantee equipment is shown as Fig. (5).

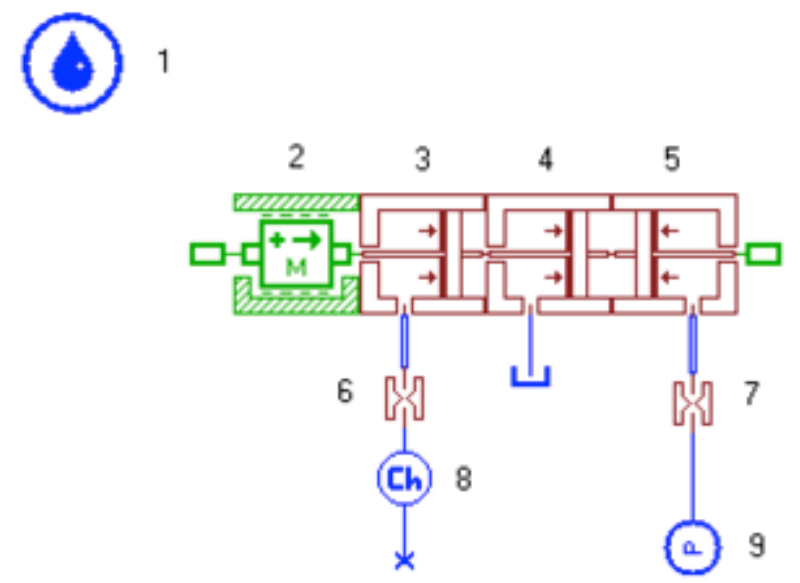

Fig. (5). Simulation model of auto-pressurized initial force guarantee equipment. 
Right piston diameter is set as $28 \mathrm{~mm}$, whereas left piston diameter is set as $22 \mathrm{~mm}$. The supercharge ratio is 1.6:1. Mass of the limit-damping block is $0.08 \mathrm{~kg}$. Viscous damping coefficient is $0.0155 \mathrm{~N} /(\mathrm{m} / \mathrm{s})$. Force of friction is $12.25 \mathrm{~N}$. Input pressure is $20 \mathrm{MPa}$. Fluids push the piston to move to the left, as fluids enter into right. High pressure fluids export into the system from left $[12,13]$. The pressure curve of prop after using auto-pressurized initial force guarantee equipment is shown as Fig. (6).

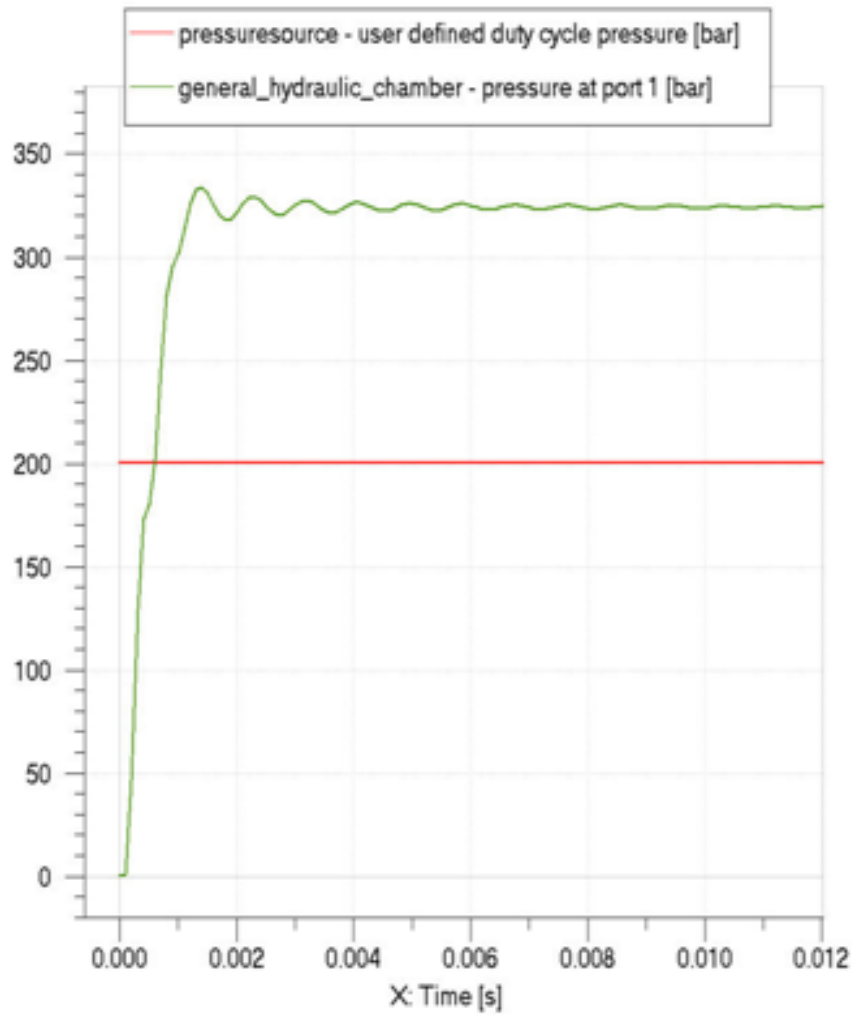

Fig. (6). The prop bottom cavity pressure curve when pressure ratio is $1.6: 1$.

Pressurizing result obtained by the output curve of pressure increasing valve is satisfactory and conforms to supercharge ratio of 1.6:1. Output pressure appears short and slight fluctuation occurs after pressure getting rated value in the initial phase. When pressure increasing valve is opening, opening area of valve port is broken, and force equilibrium state on the valve spool is also broken. Fluids generate impact on the valve spool. So, output pressure reaches peak value at $0.001 \mathrm{~s}$. Then, the pressure reduces quickly and turns to be steady with fast response time. In the design of pressure increasing valve, valve element vibration is fully reduced by decreasing high-pressure volume, adjusting diameter of damping hole, and increasing mass of valve element that have no influence on response time [14].

Using AMESim simulation software to analyze the pressure of inferior cavity of stand column, the output result of pressure curve of inferior cavity shows that the effect of pressurizing is positive and setting supercharge ratio is satisfied, through adopting auto-pressurized initial force guarantee equipment [15]. When the pressure of initial phase reaches the rated value, output pressure will appear slight fluctuation brevity. This case is due to the fact that the emulsion impacting effect on valve element is generated by breaking opening area of valve port and equilibrium state of valve element on the valve element when opening area of valve element is broken by the device opened, and causes the output pressure to reach the peak value within a moment. Then the pressure is reduced rapidly to be steady. The response time is very quick. Therefore, in the design of autopressurized initial force guarantee equipment, there are such measures as decreasing the volume of high pressure cavity of output end appropriately, adjusting the diameter of damping hole of control piston, and increasing the quality of valve element, that can decrease valve element shock and the influence on output pressure [16].

Hydraulic system AMESim simulation model of support liter prop is shown in Fig. (7).

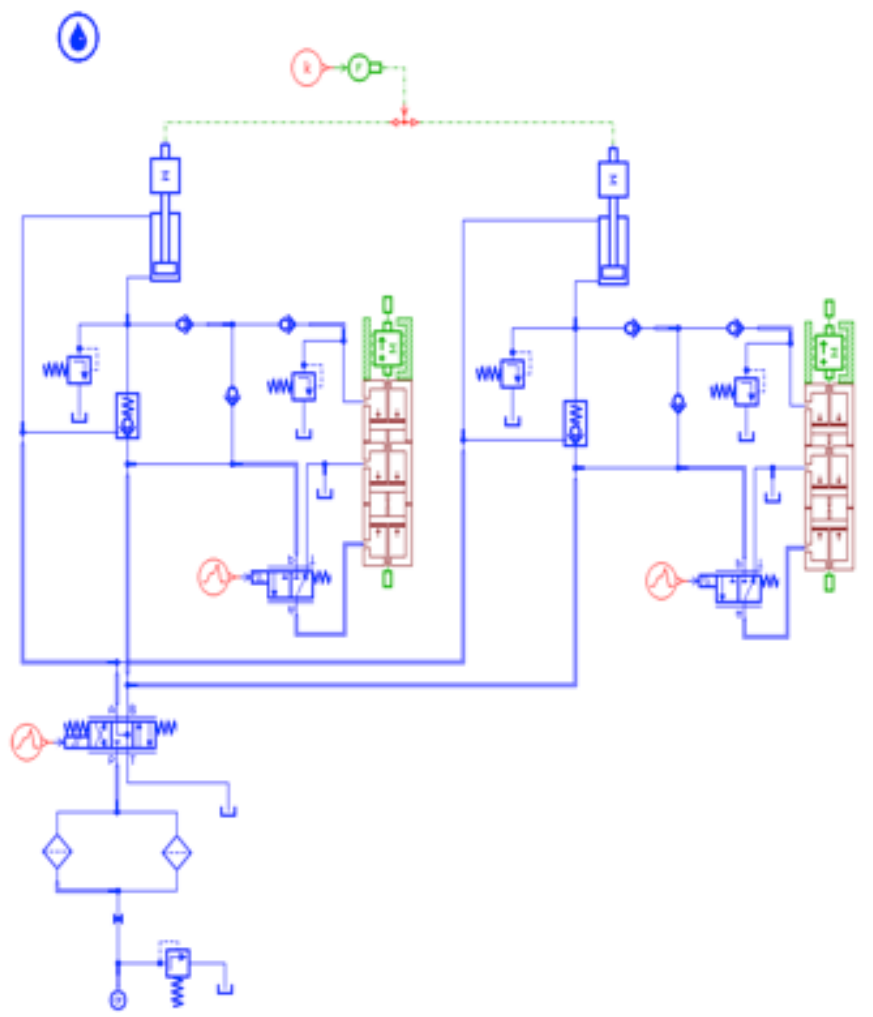

Fig. (7). Hydraulic system simulation model of support liter prop.

Rodless cavity of stand column oil cylinder of hydraulic support is set as $230 \mathrm{~mm}$, and diameter plunger $210 \mathrm{~mm}$, inlet flow $180 \mathrm{l} / \mathrm{min}$, setting prop $150 \mathrm{~mm}$, and setting pressure for safety valve in stand column $50 \mathrm{MPa}$. Starting time of simulating operation is $0 \mathrm{~s}$, and stop time $3 \mathrm{~s}$, simulation step size $10^{-5} \mathrm{~s}$, and simulation permissible error $10^{-11} \mathrm{~s}$. Standard resolver mixture error is adopted to simulate. Liquid, from constant flow source, loops through reversing valve and pilot operated check valve into the inferior cavity of stand column, and stand column begins to be elevated. Pressure build-up of inferior cavity will be will be dropped in the process of setting prop, and autopressurized equipment will be opened. Pressure of inferior cavity of stand column is reached on the design value by output high pressure liquid in order to improve the setting load for hydraulic support $[17,18]$.

The output curve of auto-pressurized initial force guarantee equipment and the system pressure equipment is obtained by analysis, as shown in Fig. (8). 
At the initial stage of opened system, liquid pressure appears with slight shock within short time that sustains about $0.01 \mathrm{~s}$. And, the pressure peak, within control area of safety valve, has no significant effect on the system. Due to the pressure loss of hydraulic system, pressure of the inferior cavity of stand column in the initial stage only reaches to 20 $\mathrm{MPa}$. Therefore, the inferior cavity of stand column is pressurized by opening the pressure increasing valve when the stage of initial support is ends at the stage of increasing resistance starts. As the output pressure curve of increasing pressure valve known, the output pressure of increasing pressure valve reaches the stable rated value after $0.1 \mathrm{~s}$. The whole stage of increasing resistance of stand column is over, and the whole process of setting prop continues for $2.08 \mathrm{~s}$, and the system is stabilized and has no large shock.

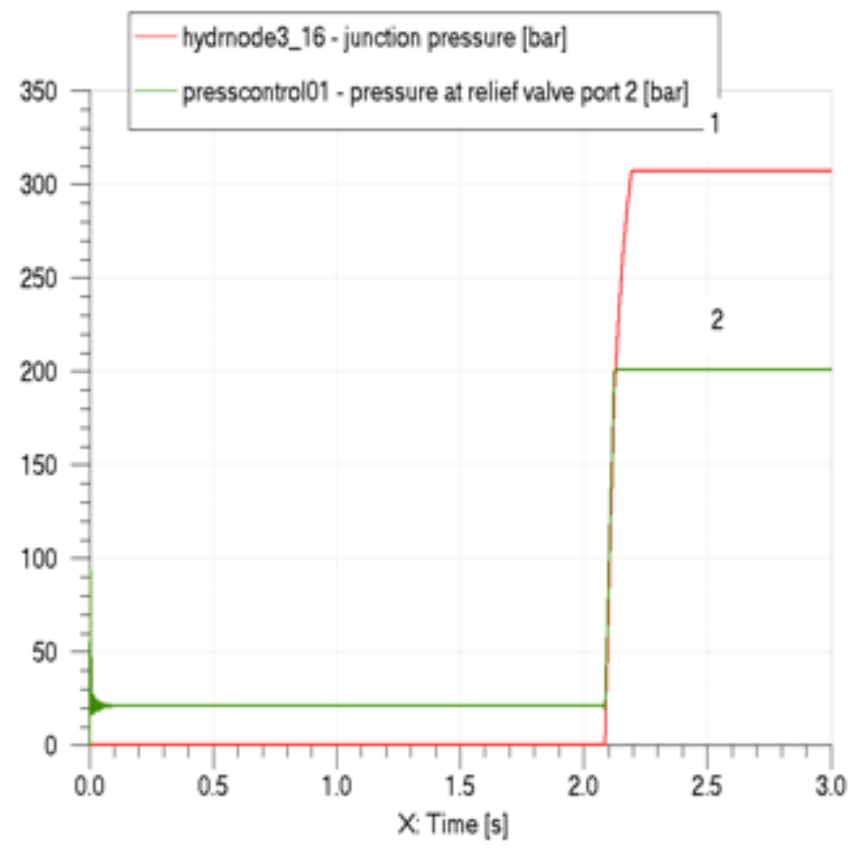

Fig. (8). The pressure curve. 1-The output pressure curve of autopressurized initial force guarantee equipment.

\section{CONCLUSION AND RESULTS}

This paper designs a device that can improve setting load of hydraulic support. The device can enhance the setting load for hydraulic support, under the circumstance that the structure of liquid valve bank of hydraulic support isn't changed and it has no influence on the normal work of liquid-inlet and rising support. Through simulated analysis of loop and practical field test, the device being used in the hydraulic support makes it more effectively that the hydraulic support system is steady and has no large shock, pressurized effect is fine, the time of increasing resistance decreased effectively in the process of setting prop, and the production safety of coal face improved.

\section{CONFLICT OF INTEREST}

We declare that we have no financial and personal relationships with other people or organizations that can inappropriately influence our work, there is no professional or other personal interest of any nature or kind in any product, service and/or company that could be construed as influencing the position presented in, or the review of, the manuscript entitled. The authors confirm that this article content has no conflict of interest.

\section{ACKNOWLEDGEMENTS}

This paper is supported by Opening Project Fund of State Key Laboratory of Mining Disaster Prevention and Control Co-founded by Shandong Province and the Ministry of Science and Technology (NO. MDPC2012KF01), the Project Fund of Colleges and Universities in Shandong Province Outstanding Young Teacher Domestic Visiting Scholar, and the Qingdao Post-doctoral Researcher Applied Research Programs: "Control Technology Research on Coupling Relationship between Coal and Support Equipment for Thick Coal Seam Mining Face".

\section{REFERENCES}

[1] L. Cao, "Study on Control System of Hydraulic Support for Large Inclined Angle Face", Ph.D. thesis, Shandong University of Science and Technology, ShanDong, China 2012.

[2] G. Wang, The Hydraulic Support Technology, Beijing: China Machine Press, 1996.

[3] C. Wang, Hydraulic Control System, Beijing: China Machine Press, 2010.

[4] Z. Xin, and Y. Zhang, Eds., "Research and application on modeling approach for electro hydraulic servo system", Journal System Simulation, vol. 21, pp. 1719-1725, 2009.

[5] W. Kemmetmuller, and S. Muller, A. Kugi, "Mathematical modeling and nonlinear controller design for a novel electrohydraulic power steering system", IEEE Trans. on Mechatronics, vol. 12, pp. 85-97, 2007.

[6] F. Shu, Study on hydraulic system for the high-end hydraulic support, China University of Mining and Technology, China, 2009.

[7] C. Wang, Numerical simulation study on solenoid valve for hydraulic support, Zhejiang University, China, 2008.

[8] J. Li, and L. Yu, Eds., "Simulation study on self-motion pressure increasing valve for hydraulic support stand column based on AMESim", Chinese Hydraulics And Pneumatics, pp. 43-45, 2011.

[9] X. Zhang, J. W. Zhang, L. R. Wan, and M. Zang, "Research on guarantee equipment for setting load of hydraulic supports". IEEE Transactions on Mechatronics (S1083-4435), vol.12, pp. 85-97. 2007.

[10] S. Yu, X. Peng, and S. Jiang, "Physical design and application on hydraulic self-motion pressure increasing valve", Journal of Central South University Of Technology, vol. 32, no. 4, pp. 414416, 2001.

[11] Y. Yubi, Y. Rubio, Eds, "Simulation analysis of booster circuit based on AME sim", Mechanical and Electronic, vol. 3, pp. 47-49, 2011.

[12] S. Hou, "Research on Setting Load Protection System and Equipment in the Single Hydraulic Prop", Ph.D. thesis, Shandong University of Science and Technology, ShanDong, China, 2006.

[13] Z. Bai, "Analysis on Impact Strength Big Bore Double Telescopic", D. thesis, Xian University of Science and Technology, ShanXi, China, 2010.

[14] X. Zhang, J. W. Zhang, L. R. Wan, and M. Zang, "Research on guarantee equipment for setting load of hydraulic supports", Applied Mechanics and Materials, vol. 44-47, pp. 2021-2025, 2011.

[15] H. Liu, and H. Li, "Modeling and simulation software AMESim and its application for hydraulic-m echanic system", Machine Tool and Hydraulics, no.6, pp.124-126, 2006.

[16] Y. Yu, C. Jia, S. Ding, and D. Chang, "Research on boost valve of powered props of powered supports", Coal Mine Machinery, vol.31, pp.52-53, 2009. 
[17] D. Zhou, C. Guo, and H. Wei, " Hydraulic-support pillar auto-boost valve modeling in AME sim and research about influence parameters", Coal Mine Machinery, vol. 34, pp. 82-85, 2013.
[18] Z. Kou, and L. Shen, "Research on auto-pressurized initial force guarantee system", Coal Science and Technology, vol. 23, pp. 8-9. 1995.

(C) Lianmin et al.; Licensee Bentham Open.

This is an open access article licensed under the terms of the Creative Commons Attribution Non-Commercial License (http://creativecommons.org/licenses/by-nc/4.0/) which permits unrestricted, non-commercial use, distribution and reproduction in any medium, provided the work is properly cited. 